\title{
Cidadania e direitos da pessoa idosa
}

Vicente de Paula Faleiros*

Resumo: Este artigo trata dos direitos da pessoa idosa nas constituições brasileiras e nas principais leis federais, numa perspectiva histórica e crítica sobre a definição desses direitos. A questão é analisada na relação entre cidadania e envelhecimento nas suas diferentes dimensões: direito à velhice, cobertura das necessidades, proteção, reciprocidade familiar e protagonismo da pessoa idosa

Palavras-chave: velhice, direitos, leis.

\section{Citizenship and elder rights}

Abstract: This article makes an analysis of the elder rights in the Brazilian Constitutions and main federal laws in a critical and historical perspective. The main category is the relationship between citizenship and aging in different dimensions like: human rights, attention, social protection, family reciprocity and protagonic role of elderly people

Keywords: old age, rights, laws.

* Assistente Social, doutor em Sociologia, professor titular aposentado e colaborador da Universidade de Brasília (UnB), pesquisador do CNPq, professor da Universidade Católica de Brasília. 


\section{Introdução}

Este artigo tem como objetivo analisar os marcos constitucionais e legais que asseguram os direitos da pessoa idosa no Brasil. Esses direitos foram elaborados e definidos, principalmente, no marco da transição democrática no Brasil pós-ditadura de 1964. A transição democrática possibilitou a expressão da transição demográfica por que passa o país. No ano de 2000, pelo Censo do IBGE havia 8,5\% de pessoas acima de sessenta anos no Brasil, alcançando em 2005 a cifra de $9,9 \%$, projetando-se $14,2 \%$ de pessoas idosas em 2020. Essa rápida transição era silenciada social, política e culturalmente. Socialmente pela não fala sobre a velhice numa sociedade considerada de jovens e voltada para a exaltação da força e da beleza física. Politicamente, o silêncio advinha em razão de mudanças nas políticas sociais com redução do papel do Estado em favorecimento do mercado e as reformas propostas traziam no seu bojo o corte de direitos sociais. Como falar em garantia de direitos num contexto neoliberal de redução de direitos?

Culturalmente, a velhice pode ser silenciada pela discriminação e pelas violências. A democratização abre espaços para manifestações de pessoas idosas, como na luta pelos $147 \%$ de reajuste nas aposentadorias durante o governo Collor, e para a organização de idosos que passaram a implementar fóruns, conselhos, centros.

A esfera do político, por sua vez, não poderia deixar de incluir o eleitorado idoso como público de marketing e de voto. Assim, a questão do envelhecimento e da pessoa idosa passa a ser considerada como questão política crucial, implicando a elaboração de um novo paradigma ou pacto societário frente ao envelhecimento demográfico e pessoal que venha contrapor o direito ao modelo filantrópico e clientelista (Faleiros, 
2001; Mestriner, 2001) e à reprivatização da velhice (Debert, 2004).

As constituições brasileiras passaram por profundas transformações no bojo dos conflitos sociais. Foi no processo de transição democrática que a Constituição de 1988 propiciou o paradigma dos direitos para a pessoa idosa assim como o paradigma da proteção integral para crianças e adolescentes.

Na primeira parte do artigo fazemos referência à política da pessoa idosa no marco constitucional, para nos referirmos mais profundamente à Constituição de 1988. Em seguida, analisamos a Política Nacional do Idoso e o Estatuto do Idoso, destacando o conceito de proteção social para abordarmos o tema da efetivação dessa proteção.

\section{Constituição e Direito}

A constituição do Estado de Direito, como pacto e como lei, torna-se o eixo de organização da vida em sociedade e do processo de fabricação do sujeito cidadão na modernidade. Trata-se, antes de tudo, de uma pactuação das forças em presença no processo de hegemonia e contra-hegemonia, como assinala Gramsci (1978, p. 71) ao afirmar que a estrutura e as superestruturas formam um "bloco histórico, o conjunto complexo, contraditório e discordante das superestruturas é o reflexo do conjunto das relações sociais de produção." Para ele, o processo dialético implica uma reciprocidade entre a estrutura e a superestrutura.

O Estado moderno, e não mais a religião, torna-se o organizador da vida social, por meio de normas que educam o indivíduo na construção de si mesmo, estabelecendo as regras de um jogo que articula a produção econômica e social com 
a produção do sujeito de direito e de deveres. Assim, não há sujeito de direitos e deveres sem Estado, não há contexto sem sujeitos. A produção da sociedade e do Estado e a produção do sujeito articulam-se de forma contraditória e combinada. A construção da cidadania passa a ser a construção da política, entendida como pactos e direitos de convivência cotidiana, de relação entre si e o outro, de relação entre grupos, num determinado território e cultura de convívio como polis, com interesses e normas definidos para todos os que sejam reconhecidos como membros de uma sociedade. Na Grécia antiga, por exemplo, os escravos, as mulheres e os estrangeiros não eram reconhecidos como membros da polis.

O direito estabelecido pelo Estado, entretanto, não basta, por si só, para definir e assegurar a cidadania de todos, pois se inscreve numa determinada correlação de forças socioeconômicas. Estabelecer direitos pode significar a cristalização do poder de um grupo dominante ou dirigente em detrimento de outros grupos, posicionando-se como uma parte dominante acima de outra parte da sociedade, fragmentando a própria sociedade entre os "com cidadania" e os "sem cidadania", ou estabelecendo apenas direitos formais para todos e reais para alguns. Esse é o eixo da crítica à cidadania burguesa, exposto por Marx (1968). Em 1843, ele disse que é necessário emanciparmo-nos politicamente como seres humanos para podermos unir o direito formalmente estabelecido às condições reais existentes, ou seja, é preciso romper com a separação entre sociedade política e sociedade civil.

Fica claro que o estabelecimento do direito formal dominante, ${ }^{1}$ da lei, não reduz, per se, a desigualdade social real, visto que a lei não é neutra; ela se inscreve num processo

1 Embora possamos encontrar várias formas de direito, inclusive o achado na rua, conforme Santos (1991). 
político de correlação de forças, de protagonismo dos sujeitos, de pressão, de exercício da palavra, de condições desiguais de impor a lei. O liberalismo econômico e político postula que a liberdade seja o fundamento da produção da sociedade, implicando, pois, uma ação desigual dos indivíduos na disputa ou concorrência para garantir seus interesses e a chamada racionalidade econômica na busca da lucratividade.

T. H. Marshall (1988), nesse contexto liberal, ${ }^{2}$ porém marcado pelo Pós-Guerra de 1945, formulou uma teoria que busca estabelecer a possibilidade de construção de um status de cidadão, comum a todos, numa desigual sociedade de classes. Segundo o autor, esse status não dissolve a sociedade de classes, mas estabelece "zonas" ${ }^{3}$ de igualdade. Essa construção da cidadania, a partir de sua visão, seria um processo evolutivo de vários séculos. Distinguiu três momentos e dimensões da cidadania: a civil, como expressão do direito à liberdade; a política, como expressão do voto; a social, como garantia da educação e de mínimos sociais. A cidadania civil, segundo o autor, se constituiu no século XVIII; a política, no século XIX; e a social, no século XX. Essa divisão tripartite, no entanto, como assinala Barbalet (1989), não levou em conta as lutas sociais e as lutas de classes na implementação da cidadania nem a visão da cidadania como participação. A dinâmica de construção da cidadania, de fato, passa pelo reconhecimento de direitos do ponto de vista jurídico, implicando, no entanto, uma dinâmica contraditória de lutas e de forças entre a estruturação legal e a vida social real.

A Declaração Universal dos Direitos Humanos, de 1948, traz, como fundamento desses direitos, a dignidade do ser humano, por deliberação consensual dos Estados

2 Seu texto foi elaborado em 1949.

3 Expressão nossa. 
participantes. Por sua vez o Pacto dos Direitos Econômicos, Sociais e Culturais, aprovado em 1966 e ratificado pelo Brasil em 1992, traz como referência a indivisibilidade dos direitos econômicos, sociais e culturais, sem nenhuma discriminação de raça, sexo, religião, língua, opinião política ou qualquer opinião, origem nacional, nascimento, fortuna ou qualquer outra situação. Essa perspectiva foi contemplada na Constituição de 1988, pois, nas anteriores, os idosos só foram reconhecidos como trabalhadores fora do mercado ou desvalidos, como veremos.

\section{Direitos das pessoas idosas nas constituições brasileiras}

A Constituição de 1934 referia-se à velhice como uma etapa improdutiva que merecia favor e apoiava a filantropia das instituições de caridade para idosos. Somente haveria direito se a pessoa tivesse sido inscrita na produção. Assim, os direitos da pessoa idosa foram inscritos da Constituição de 1934 (art. 121, item h) como direitos trabalhistas, na implementação da previdência social "a favor da velhice". Ao se tornar improdutivo, na era industrial, o sujeito passava a ser considerado velho, a partir do pressuposto de sua exclusão da esfera do trabalho, como operário. Ao trabalhador rural de então não foram reconhecidos direitos trabalhistas, pois ficava na esfera do "aluguel de mão-de-obra" sob a tutela da oligarquia rural (Faleiros, 2007).

O amparo aos desvalidos na Constituição de 1934 previa serviços especializados e "animação de serviços sociais" (art. 138), dentro da visão eugênica e higienista, de socorro às famílias de prole numerosa e no combate "aos venenos sociais". Previa também a previdência social "a favor da velhice" com contribuição tripartite do empregador, do empregado e da União, numa clara referência à transição industrial. 
A Constituição de 1937 (art. 137) reafirmava o seguro de velhice para o trabalhador.

Em ambas as constituições, invocava-se a proteção do Estado para a subsistência e educação de prole numerosa, mas a de 1937, no art. 127, assinalava que esse direito cabia aos "pais miseráveis" (sic!). Tanto no Código Civil de 1917, como no de 2002, foi estabelecido o direito de alimentos, recíproco entre pais e filhos.

A Constituição de 1946 (art. 157) dispunha sobre a formulação de previdência "contra as conseqüências da velhice", ampliando a idéia de um seguro social somente para trabalhadores industriais, e a Constituição de 1967 estabelecia a previdência social "nos casos de velhice" (art. 158).

Nas constituições citadas também estava contemplada a assistência à maternidade, à infância e à adolescência. A previdência, em realidade passou, então, a contemplar também a assistência à saúde, alguns benefícios pecuniários e pensões que foram regulamentados por lei, mas dentro da esfera contributiva.

Quando a velhice passa de uma questão filantrópica e privada para a esfera pública, a perspectiva dominante passou a ser a incorporação do direito do trabalhador e não o direito da pessoa envelhecente. Ao mesmo tempo, manifestava-se que a velhice tinha uma relação profunda com a privacidade, o âmbito da família e o âmbito da filantropia e da religião. As Sociedades São Vicente de Paula tentavam manter a família assistida em lares subsidiados e os asilos atendiam àqueles privados de laços familiares e de renda. A Legião Brasileira de Assistência, fundada em 1943, possuía alguns programas para idosos, como o apoio a asilos.

Foi uma instituição ligada aos trabalhadores, o Serviço Social do Comércio (Sesc) - entidade patronal financiada 
pelos trabalhadores e consumidores - que, a partir de 1963, passou a promover atividades abertas a idosos, nos seus centros de convivência e fora do âmbito filantrópico, religioso ou estatal. Essas atividades destinadas a idosos representaram, no entanto, um espaço de consideração da velhice como um momento da vida, como uma esfera especial.

Nos anos 70, em plena ditadura, segundo Nara Rodrigues (2005), o fato mais importante foi a Lei no 6.119/74, que instituiu as Renda Mensal Vitalícia, no valor de $50 \%$ do salário mínimo para maiores de 70 anos que houvessem contribuído, ao menos um ano, para a Previdência. O INPS, em 1975, passou a apoiar os centros de convivência. No final dos anos 70, as pessoas idosas começaram a se organizar em associações, quando também o Ministério da Saúde se voltou para a questão. Em 1982 surgiram as primeiras Universidades da Terceira Idade. Segundo Nara Rodrigues (2005, p. 88), na década de 80, continuou a expansão dos grupos de convivência articulados a várias organizações. Em 1990 foi organizada a Confederação Brasileira de Aposentados (Cobap), que se aplicou na luta pelos valores das aposentadorias, pelos direitos sociais e pela cidadania da pessoa idosa.

\section{A Constituição de 1988}

A Constituição de 1988 reflete um pacto social fundado na democratização da sociedade, na garantia de direitos e na implementação de uma forma de organização política que viesse superar o centralismo e a fragmentação de políticas sociais e que aprofundasse o federalismo, o municipalismo e o protagonismo das pessoas. Isso acarretará implicações nas políticas para os idosos. 
Os direitos da pessoa idosa estão presentes nos capítulos da assistência, da família, do trabalho e da previdência, mas também aparecem tanto na área dos direitos decorrentes da solidariedade ou reciprocidade, como de cobertura de necessidades (não contributivos) e em decorrência da contribuição e do trabalho. Vamos detalhar essas dimensões presentes na Constituição de 1988 com destaque para: envelhecimento e necessidades, defesa da dignidade, proteção social e protagonismo.

A cobertura de necessidades com benefícios não contributivos

É no artigo 203 da Constituição Federal que se garante o benefício de um salário mínimo mensal à pessoa portadora de deficiência e ao idoso que comprovem não possuir meios de prover a própria manutenção ou de tê-la provida por sua família, conforme dispuser a lei.

Há uma condicionalidade na lei que remonta à "miserabilidade", mas que se expressa de forma distinta, segundo o critério das necessidades, pois no mesmo artigo se afirma que "a assistência social será prestada a quem dela necessitar, independentemente de contribuição à seguridade social". Não é à previdência que a lei se refere, mas à seguridade social.

No artigo 204 acrescenta-se que a assistência social deve ser descentralizada e participativa, com coordenação e normas gerais de competência da esfera federal, cabendo "a coordenação e a execução dos respectivos programas às esferas estadual e municipal, bem como a entidades beneficentes e de assistência social". Nesse mesmo artigo está especificada a "participação da população por meio de 
organizações representativas, na formulação das políticas e no controle das ações em todos os níveis", ou seja os idosos são protagonistas da política de assistência.

No domínio da previdência contributiva e da filiação obrigatória (art. 201), prevê-se a cobertura dos eventos de doença, invalidez, morte e idade avançada, além de se estabelecer pensão por morte do segurado. Com as Reformas da Constituição foi extinta a aposentadoria por tempo de serviço, que só é concedida, no regime geral, aos 35 anos de contribuição se homem, e 30, se mulher. A aposentadoria por idade é concedida ao homem aos 65 anos e à mulher aos 60 , com período de contribuição que deverá chegar aos 180 meses, no mínimo em 2011, mas, de acordo com o fator previdenciário, que leva em conta a longevidade da população, o benefício pode ser reduzido conforme a idade na época de sua demanda. Quanto menor a idade de aposentadoria, menor o benefício.

O impacto do envelhecimento está fazendo com que haja um incentivo ao requerimento numa idade mais avançada, como já está explícito no caput do art. 201. Cada vez mais, os governos estão levando em conta não o conceito de velhice, mas o de idade avançada, ou seja, a maior longevidade.

O art. 40 assegura a aposentadoria aos servidores públicos mediante contribuição (hoje de $11 \%$ no governo federal) dos ativos, inativos e pensionistas e dos entes públicos respectivos.

Entre os direitos sociais (art. 6ㅇ), encontra-se a previdência social, e entre os direitos dos trabalhadores urbanos e rurais está prevista a aposentadoria (inciso XXIV do art. $7^{\circ}$ ).

O direito à saúde não se restringe ao idosos, sendo "direito de todos e dever do Estado", levando em conta também as necessidades relativas à autonomia da pessoa idosa. 
A família e a defesa da dignidade

Se, no âmbito da seguridade social, tem-se o conceito de cobertura de necessidades (embora de forma restrita) com vistas à manutenção da renda e da autonomia, no âmbito da família, a Constituição se refere ao idoso na defesa da dignidade e da participação, e não só ao princípio da reciprocidade alimentar, como o faz o Código Civil.

Como assinalamos, a Convenção Internacional dos Direitos Humanos (do Homem), de 1946, se fundamenta no conceito de dignidade. $\mathrm{Na}$ defesa da dignidade das pessoas idosas, a Constituição brasileira de 1988, em seu artigo 230, coloca, de maneira clara, que a família, a sociedade e o Estado têm o dever de ampará-las, "assegurando sua participação na comunidade, defendendo sua dignidade e bem-estar e garantindo-Ihes o direito à vida".

Assinala também, no $\S 1^{\circ}$ do referido artigo, a prioridade do atendimento ao idoso no domicílio ou no lar: "Os programas de amparo aos idosos serão executados preferencialmente em seus lares", obrigando o Estado ao atendimento domiciliar, de forma preferencial.

O princípio da reciprocidade entre pais e filhos é claramente expresso no artigo 229: "Os pais têm o dever de assistir, criar e educar os filhos menores, e os filhos maiores têm o dever de ajudar e amparar os pais na velhice, carência ou enfermidade".

Algumas constituições, como a cubana, só colocam a responsabilidade do Estado para idosos sem recursos e sem amparo, mas, no Brasil e em alguns países da Europa, como a Espanha e a Itália, segundo Sousa (2004, p. 29), as constituições têm como referência a dignidade e abrangem todas a pessoas, sem a especificação do abandono. 
É importante salientar que as pessoas idosas são cidadãos e cidadãs com direitos iguais perante a lei, mas o artigo $5^{\circ}$, no inciso XLVIII, dispõe que a pena será cumprida de acordo com a natureza do delito, a idade e o sexo do apenado.

Outro item da Constituição que se refere aos idosos é o $\S 1^{\circ}$, inciso II, alínea "b", do artigo 14, que isenta os maiores de 70 anos da obrigatoriedade do voto.

Esses direitos e esse reconhecimento constitucional se traduz, infraconstitucionalmente, em várias leis, cuja centralidade é a proteção, o protagonismo e a prioridade.

A garantia e a efetivação dos direitos

Várias leis federais, estaduais e municipais garantem à pessoa idosa a efetivação de direitos especiais em função da trajetória de vida que se manifesta na velhice (Barroso, 2001; Brasil. Senado, 2008). Esses direitos especiais são uma forma de levar em conta a realidade do envelhecimento social e individual.

Com efeito, o envelhecimento diz respeito a processos biopsicossocioculturais multidimensionalmente articulados. O conceito de velhice, associado negativamente a perdas, ou positivamente a ganhos e conquistas, faz parte da visão contraditória da velhice (Faleiros, 2006). Essa multidimensionalidade e essa visão de ganhos e perdas fazem parte da organização da legislação. Com efeito, a grande maioria dos idosos (cerca de $80 \%$ ) vive de maneira autônoma e independente, mas numa etapa de vida em que existe a previsibilidade de uma dinâmica complexa de equilibração das várias dimensões implicadas nas perdas biológicas, no desenvolvimento pessoal e nas condições sociais. 
A legislação traduz tanto a necessidade de proteção como o incentivo ao protagonismo, à participação e à qualidade de vida, dimensões que, de fato, devem ser articuladas na implementação das políticas sociais formalmente assinaladas na Constituição. Vamos levá-las em conta nos itens abaixo, destacando apenas a legislação que, no âmbito federal, assegura a proteção, a participação e a qualidade de vida.

\section{Proteção social à pessoa idosa}

A cobertura de necessidades que se implementa, fundamentalmente, pela proteção social implica a seguridade social. A seguridade, na própria Constituição (art. 194), está definida como direito à assistência, à previdência e à saúde, com ações tanto dos poderes públicos e da sociedade, as quais devem conformar um conjunto integrado.

A proteção social, no âmbito da assistência social, implica tanto a garantia de renda como de serviços especializados, conforme a Lei no 8.742, de 7 de dezembro de 1993 - Lei Orgânica da Assistência Social (LOAS) e a Política Nacional de Assistência Social (PNAS/2004).

De acordo com a LOAS, em seu artigo $2^{\circ}$, a assistência social tem entre seus objetivos: "a proteção à família, à maternidade, à infância, à adolescência e à velhice" (inciso I) e "a garantia de 1 (um) salário mínimo de benefício mensal à pessoa portadora de deficiência e ao idoso que comprovem não possuir meios de prover a própria manutenção ou de tê-la provida por sua família" (inciso VI).

Para efeitos legais, a família cuja renda mensal per capita seja inferior a 1/4 (um quarto) do salário mínimo (§ $3^{\circ}$ do art. 20) é considerada incapaz de prover a manutenção da pessoa portadora de deficiência ou idosa. Para inclusão no benefício, 
é necessário completar 65 anos, conforme o Estatuto do Idoso, de 2003. Dessa forma, a proteção se efetiva, em primeiro lugar, pela garantia de renda aos idosos mais pobres. No entanto, o conceito de proteção envolve não somente renda, mas também serviços que devem ser prestados de forma integrada, descentralizada e participativa, tanto para o enfrentamento da pobreza como para o "provimento de condições para atender contingências sociais e à universalização dos direitos sociais" (arts. $2^{\circ}$ e $6^{\circ}$ ).

No artigo 23 da LOAS fica claro que a proteção, por meio de serviços, implica "atividades continuadas que visem à melhoria de vida da população e cujas ações, voltadas para as necessidades básicas, observem os objetivos, princípios e diretrizes estabelecidas nesta lei", inclusive "programas de amparo às pessoas que vivem em situação de rua" (incluído pela Lei no 11.258, de 2005).

A proteção vincula-se a um sistema de garantias de direitos, com participação da sociedade e dos sujeitos de direitos. $\mathrm{Na}$ PNAS (Resolução CNAS no 145/2004), a proteção é definida como uma segurança de rendimento, de autonomia, de convívio ou vivência familiar, de cuidados e serviços e de projetos operados em rede. A proteção se dispõe em rede e supõe um sistema, embora sistema e rede sejam formas distintas de organização. Na Norma Operacional Básica do Sistema Único de Assistência Social (SUAS) - que implementa o art 6음 da LOAS - a proteção social "consiste no conjunto de ações, cuidados, atenções, benefícios e auxílios ofertados pelo SUAS para redução e prevenção do impacto das vicissitudes sociais e naturais ao ciclo da vida, à dignidade humana e à família como núcleo básico de sustentação afetiva, biológica e relacional". Assim, a proteção social implica, ao mesmo tempo, direitos, sistema de garantias, rede de atores e compromisso. 
Está pressuposto, nessa perspectiva, que o fundamento da proteção são os direitos humanos, como norma consensuada universal da dignidade do ser humano. O sistema de assistência conforma a estrutura articulada para a efetivação desses direitos, resultantes de pactos políticos, de leis e de normas, segundo a correlação de forças da sociedade, do mercado e do Estado, configurando a cidadania protegida e não apenas declarada na lei.

Para ser considerado cidadão ou cidadã, a pessoa precisa ter asseguradas, pelo Estado e pela sociedade, as condições de vida digna na sua história e na sua trajetória. A pessoa torna-se credora do Estado de Direito para viver e conviver com liberdade, igualdade, justiça e eqüidade democraticamente estabelecidas.

A rede de proteção também faz parte do pacto democrático que, territorialmente, foi construído pelo compromisso dos atores e gestores do sistema, com participação dos sujeitos e da sociedade organizada. O pacto constitucional que estabelece a proteção se traduz na lei que garante direitos, mas só se efetiva no pacto de cuidados e serviços articulados, com participação (protagonismo) do sujeito, com recursos e pessoal, e com compromissos dos gestores do sistema. A sociedade só se torna menos injusta se houver efetividade do pacto na redução das desigualdades e das iniqüidades. Nesse sentido, a proteção social implica uma dinâmica permanente (ou permanência de uma dinâmica, mesmo paradoxal) de contratualização dos atores e agentes sociais para garantir e efetivar direitos estabelecidos.

Ainda que, na sociedade capitalista, a cidadania seja um movimento pelos direitos, e seu sistema e sua proteção sempre inconclusos e incompletos, sua efetivação histórica é processual, dependendo da mobilização e da organização 
dos atores da sociedade e gestores. A proteção cidadã é essencialmente participativa, pois implica o re-conhecimento do sujeito no deciframento comum de suas condições e de seus direitos para o compromisso real de efetivá-los. A proteção social visa à vida digna, com redução das incertezas e inseguranças provenientes da própria desigualdade capitalista, dos ciclos familiares e individuais e dos conflitos sociais com a satisfação das necessidades fundamentais dentro de um padrão normativo democrático de cidadania.

A LOAS (art. 24) assinala ainda que "os programas serão definidos pelos respectivos Conselhos de Assistência Social, obedecidos os objetivos e princípios que regem esta lei, com prioridade para a inserção profissional e social".

No âmbito da Previdência Social, a efetivação dos direitos se expressa principalmente, na garantia de renda pela aposentadoria, complementada por outros benefícios. Foge do propósito deste artigo analisarmos a Lei no 8.212/91 e suas modificações; no entanto, é preciso destacar que a aposentadoria depende tanto da idade como do tempo de contribuição, visto que se trata de um benefício vinculado ao pagamento feito durante a vida a um fundo previdenciário. Para esse fundo contribuem patrões e empregados e seus benefícios são usufruídos em caso de velhice, invalidez, acidente, doença, desemprego e morte. Neste caso são os dependentes que recebem pensão ou pecúlio.

A proporção de idosos está aumentando no conjunto da população e esta questão traz à tona o impacto da transição demográfica na previdência social que também depende do tipo ou modelo de financiamento e de pagamento de benefícios. A Constituição de 1988 incorporou de forma plena os trabalhadores rurais com benefícios não contributivos e mudou a forma de financiamento. A Reforma de 1998 cancelou 
a aposentadoria por tempo de serviço, mudando-a para tempo de contribuição. A Reforma de 2003 mudou a Previdência Social do Setor Público com critérios de idade e contribuição.

O índice de envelhecimento - a razão entre o total da população acima de 60 anos e a população com menos de 15 anos -, deve aumentar 6,6 vezes de 1984 a 2050, passando de 0,185 para 1,412 (Ipea, 2006). O total de empregados contribuintes em 2000 era de $30,9 \%$ da PEA, o de autônomos $4,3 \%$, o de funcionários $4,3 \%$ e o de empregadores $1,8 \%$, totalizando-se apenas $41,8 \%$ da PEA. A crise econômica faz diminuir o emprego formal e aumentar a informalidade.

No entanto, $78 \%$ da população idosa do Brasil está coberta pela Previdência Social (aposentadoria ou pensão), sendo esse índice maior no Nordeste $(83,4 \%)$, segundo dados de 2003 (Ipea, 2005). Essa cobertura mostra que a proteção social contributiva tem um impacto significativo na garantia da renda, complementada pela proteção não contributiva do Benefício de Prestação Continuada, que atingiu 1.183.840 pessoas em 2006 (Brasil. MS, 2006), atingindo 6,2\% dos idosos mais pobres. O Bolsa Família atinge 11 milhões de famílias muito pobres, propiciando até $\mathrm{R} \$ 120,00$ por família, cujo maior uso é em alimentação (Weissheimer, 2006).

No domínio da saúde, contata-se que a presença do Sistema Único de Saúde (SUS) nos atendimentos aos idosos é muito significativa para os mais pobres, pois $90 \%$ dos $30 \%$ mais pobres usam o SUS. Na pesquisa Sesc/Fundação Perseu Abramo (2007), 68\% dos idosos pesquisados declaram utilizar o SUS, e $24 \%$ usam planos particulares.

$\mathrm{Na}$ política de atendimento, os idosos foram incluídos como prioridade no Pacto da Saúde de 2005, e na Portaria no 2.528, de 2006, foi definida a Política Nacional de Saúde da 
Pessoa Idosa que se articula à determinação constitucional do atendimento em domicílio, tendo como porta de entrada a Atenção Básica/Saúde da Família.

A promoção da autonomia e da participação

A garantia de proteção - cobertura de necessidades está articulada à autonomia e à participação. Conforme a Lei no 8.842, de 4 de janeiro de 1994, a Política Nacional do Idoso (PNI) "tem por objetivo assegurar os direitos sociais do idoso, criando condições para promover sua autonomia, integração e participação efetiva na sociedade" (art. 1ํ), com articulação da família, do Estado e da sociedade, "defendendo sua dignidade, bem-estar e o direito à vida" (art 3). Para isso, a PNI prevê a participação no relacionamento intergeracional e por meio de organizações representativas num sistema descentralizado, conforme prevê a Constituição.

Na prática, os conselhos traduzem uma possibilidade de democracia participativa e de controle democrático das ações do governo. O Conselho Nacional do Idoso (CNDI) reuniu-se, pela primeira vez, no primeiro semestre de 2003 e hoje existem conselhos estaduais da pessoa idosa em todos os Estados. O Estatuto do Idoso assinala que "compete aos conselhos a supervisão, o acompanhamento, a fiscalização e a avaliação da política nacional do idoso. No entanto faltou estabelecer, nessa lei, o caráter deliberativo dos conselhos, o que foi corrigido pelo Decreto no 5.108, de 17 de junho de 2004, onde fica claro que o Conselho Nacional de Direitos do Idoso (CNDI) é "um órgão colegiado de caráter deliberativo, integrante da estrutura básica da Secretaria Especial dos Direitos Humanos da Presidência da República, tendo por finalidade elaborar as diretrizes para formulação e implementação da política nacional 
do idoso, bem como acompanhar e avaliar a sua execução" (Faleiros, 2006).

Assim, as leis de 1994 e de 2003 foram reconfiguradas pelo decreto de 2004 que propicia condições deliberativas, determinando o caráter participativo do Conselho, pois pode influir na política.

Além disso, já foi realizada a 1a Conferência Nacional dos Direitos da Pessoa Idosa, de 23 a 26 de maio de 2006, com a participação de 725 pessoas, provenientes de todas as Unidades da Federação. Num questionário respondido pelos participantes, a principal estratégia indicada foi trabalhar a relação intergeracional na família e na escola. (Conferência..., 2006, p. 110).

A garantia da renda, da saúde e da proteção social devem ser complementadas com à prestação de serviços à pessoa idosa.

A diversidade do atendimento: convivência, dependência e combate à violência

Vamos destacar na legislação, três tipos fundamentais de serviços que são: os serviços para a convivência, para o cuidado da dependência e para o combate à violência. Esses três tipos de atendimento referem-se não somente às problemáticas mais urgentes, como também à heterogeneidade da velhice. A velhice é heterogênea (Faleiros, 2006) e as demandas são complexas, decorrendo não apenas da perda da renda ou da necessidade de atendimento à saúde, mas das condições de convivência, de dependência e de situações de violência.

Em São Paulo, conforme dados do projeto SABE (Duarte, Lebrão e Lima, 2005), constatou-se que $22,1 \%$ dos idosos 
disseram ter muita limitação de atividades e 40,5\% pouca limitação, sendo que $37,4 \%$ não se referiram a nenhuma. Também ficou constatado que $12,9 \%$ dos idosos têm alguma deterioração cognitiva, mas $80 \%$ têm condições de autocuidado. No entanto, $60,6 \%$ dos idosos declararam não receber qualquer tipo de auxílio, e os arranjos familiares que mais supriam as demandas assistenciais referem-se aos arranjos trigeracionais e àqueles que contavam com a presença de não familiares, possivelmente cuidadores (Duarte, Lebrão e Lima, 2005).

Dessa forma, recai sobre a família o cuidado dos idosos dependentes, embora a legislação preveja várias alternativas de serviços, cabendo à assistência social, de acordo com a $\mathrm{PNI}$,

prestar serviços e desenvolver ações voltadas para o atendimento das necessidades básicas do idoso; estimular a criação de incentivos e de alternativas de atendimento ao idoso, como centros de convivência, centros de cuidados diurnos, casas-lares, oficinas abrigadas de trabalho, atendimentos domiciliares e outros; promover simpósios, seminários e encontros específicos; planejar, coordenar, supervisionar e financiar estudos, levantamentos, pesquisas e publicações sobre a situação social do idoso; promover a capacitação de recursos para atendimento ao idoso.

Além da assistência, da saúde e da previdência, a PNI prevê ações nas áreas da educação, trabalho, habitação e urbanismo, justiça, cultura, esporte e lazer. Quanto ao atendimento asilar ou por meio de instituições de longa permanência, embora esteja previsto na PNI, no Brasil ele ainda é relativamente pequeno, pois no Censo de 2000 havia apenas 103.000 idosos em domicílios coletivos, o que representava $0,8 \%$ da população idosa. 
Como já assinalamos, o Ministério da Saúde estabeleceu uma política de atendimento domiciliar tanto pela Estratégia de Saúde da Família, como pelo incentivo à implementação de serviços domiciliares em co-parceria com Estados e municípios, conforme a Portaria no 2.529, de 19 de outubro de 2006, que "institui a internação domiciliar no âmbito do SUS", com prioridade para o idoso, dispondo o governo federal de $\mathrm{R} \$ 20.000,00$ por equipe por mês, tendo como meta a média de 30 internações/mês por equipe. Por sua vez, o Serviço de Assistência Médica de Urgência (SAMU) pode atender as demandas emergenciais, conforme o município tenha organizado o serviço.

De fato, as legislações municipais vão dando maior ou menor importância à prestação de serviços à pessoa idosa, mas o abrigamento ainda está, na maioria, sob a égide da filantropia.

O combate à violência está articulado por um Plano Nacional de Enfrentamento da Violência à Pessoa Idosa, mas, além de alguns centros vinculados ao âmbito dos direitos humanos, são os Centros de Referência Especializados em Assistência Social (Creas) e o Ministério Público que oferecem serviços e ações judiciais, respectivamente, para a defesa dos idosos.

Existe grande variedade de centros de convivência de idosos que propiciam oportunidades de troca social e de lazer, cultura e atividades físicas. Em 2005, havia 54 grupos de convivência registrados no Distrito Federal. O Sesc (2003) foi pioneiro na constituição desses grupos, tendo hoje centros de convivência com demanda maior de inscrições em função do aumento de aposentados.

Por outro lado, existem as escolas abertas da terceira idade, as Universidades da Terceira Idade, e uma maior 
inserção dos idosos no voluntariado. O Ministério do Esporte vem apoiando atividades físicas para idosos.

\section{Direito à velhice e à prioridade}

No Estatuto do Idoso, Lei no 10.741 , de 1 de outubro de 2003, é que se estabelece o direito à velhice de forma bem explícita, com deveres e obrigações da família, da sociedade e do Estado. Assim reza o artigo $3^{\circ}$ dessa lei:

É obrigação da família, da comunidade, da sociedade e do Poder Público assegurar ao idoso, com absoluta prioridade, a efetivação do direito à vida, à saúde, à alimentação, à educação, à cultura, ao esporte, ao lazer, ao trabalho, à cidadania, à liberdade, à dignidade, ao respeito e à convivência familiar e comunitária.

Agarantia da prioridade compreende, além do atendimento preferencial, também:

- preferência na formulação e na execução de políticas sociais públicas específicas;

- destinação privilegiada de recursos públicos nas áreas relacionadas com a proteção ao idoso;

- viabilização de formas alternativas de participação, ocupação e convívio do idoso com as demais gerações;

- priorização do atendimento do idoso por sua própria família, em detrimento do atendimento asilar, exceto dos que não a possuam ou careçam de condições de manutenção da própria sobrevivência;

- capacitação e reciclagem dos recursos humanos nas áreas de geriatria e gerontologia e na prestação de serviços aos idosos; 
- estabelecimento de mecanismos que favoreçam a divulgação de informações de caráter educativo sobre os aspectos biopsicossociais do envelhecimento;

- garantia de acesso à rede de serviços de saúde e de assistência social locais.

É no artigo 8ㅇqu fica explicitado que "o envelhecimento é um direito personalíssimo e a sua proteção um direito social, nos termos desta Lei e da Legislação vigente".

Na prática cotidiana, os direitos são violados das mais variadas formas, tanto pelo poder público como pela família e pela sociedade e o Estatuto garante as diferentes possibilidades de ação para que o Ministério Público, na tutela desses direitos, "com a ressalva de que, embora a repressão penal seja um importante instrumento para a tutela de direitos" (Godinho, 2007 p. 3).

A idade é um critério jurídico para a definição de direitos e deveres e pode-se aplicar tanto a crianças e adolescentes como aos idosos, embora esse critério não seja, muitas vezes, pacificamente aceito diante da universalização dos direitos. $O$ Estatuto do Idoso explicita esses direitos universais de forma específica a assegurar a proteção social e, no artigo $4^{\circ}$, o direito de todos é também direito do idoso e o direito do idoso é direito de todos, rezando:

nenhum idoso será objeto de qualquer tipo de negligência, discriminação, violência, crueldade ou opressão, e todo atentado aos seus direitos, por ação ou omissão, será punido na forma da lei.

Sendo cidadão de plenos direitos, o idoso deve ser atendido de forma tal que se garanta sua autonomia, ou seja, sua capacidade de decisão, mesmo nas instituições de longa permanência, como estabelece o art. 35 do Estatuto: "todas as 
entidades de longa permanência, ou casa-lar, são obrigadas a firmar contrato de prestação de serviços com a pessoa idosa abrigada".

\section{Considerações finais}

Levando-se em conta os dispositivos da Constituição, das leis federais, dos decretos e também de legislações estaduais e municipais, podemos concluir que, ao mesmo tempo em que vive uma transição demográfica e epidemiológica, o Brasil está numa transição jurídica para o reconhecimento, no contexto democrático, dos direitos da pessoa idosa enquanto sujeito de direitos à cobertura das necessidades, à dignidade, à velhice, à proteção e ao protagonismo.

Em primeiro lugar, já não há dúvida da consolidação tanto do direito à velhice digna e protegida como também dos direitos individuais e coletivos das pessoas idosas. Esses direitos estão se corporificando numa rede de proteção que envolve vários órgãos públicos e que está em processo de construção pela formulação, ainda inicipiente, da Rede Nacional de Proteção e Defesa da Pessoa Idosa (Renadi). Em 2006 foi realizado o IV Encontro Nacional de Conselhos de Idosos, quando se fez o levantamento dos atores envolvidos nessa rede, destacandose os órgãos públicos do Executivo e do Judiciário, a mídia, as universidades e sociedades científicas, as organizações sindicais e empresariais, e as ONGs. Esses órgãos ainda não atuam em rede, como definido acima, mas pressupõe-se um compromisso entre eles. Cada ação, entretanto, implica uma articulação diferente de atores.

Essa rede está assentada na garantia dos direitos fundamentais da pessoa humana, conforme 0 artigo $5^{\circ}$ da Constituição, que leva em conta a Declaração Universal dos 
Direitos Humanos. O eixo dessa rede é, pois, a dignidade da pessoa humana e o protagonismo da pessoa idosa, com o objetivo estratégico de manutenção e desenvolvimento da autonomia e independência dos idosos considerando um "envelhecimento ativo".

A OMS (2005) esclarece os termos relativos à velhice ativa:

- envelhecimento ativo "é o processo de otimização das oportunidades de saúde, participação e segurança com o objetivo de melhorar a qualidade de vida à medida que as pessoas ficam mais velhas".

- autonomia "é a habilidade de controlar, tomar decisões pessoais sobre como se deve viver diariamente, de acordo com suas próprias regras e preferências".

- independência é "em geral, entendida como a habilidade de executar funções relacionadas à vida diária - isto é, a capacidade de viver independentemente na comunidade com alguma ou nenhuma ajuda de outros".

- qualidade de vida "é a percepção que o indivíduo tem de sua posição na vida dentro do contexto de sua cultura e do sistema de valores onde vive, e em relação a seus objetivos, expectativas, padrões e preocupações. Incorpora de uma maneira complexa a saúde física de uma pessoa, seu estado psicológico, seu nível de dependência suas relações sociais, suas crenças e sua relação com características proeminentes no meio ambiente".

Em segundo lugar, também está previsto um sistema de políticas ou de garantia de direitos, que deve ser integrado, descentralizado e participativo. 


\section{Referências bibliográficas}

BARROSO, Celeste Taques Bittencourt (Org.). O idoso no direito positivo brasileiro. Brasília: Ministério da Justiça/SEDH, 2001.

BRASIL. Ministério do Desenvolvimento Social e Combate a Fome. Secretaria Nacional de Assistência Social. Financiamento da Assistência Social no Brasil. Brasília, 2007. (Caderno SUAS, n. 2).

Ministério da Saúde. Secretaria de Atenção à Saúde. Departamento de Atenção Básica. Envelhecimento da pessoa idosa. Brasília, 2006. (Caderno de atenção básica n. 19).

Ministério da Previdência e Assistência Social. Portaria no 73 de 10/05/2001. Normas de Padrões Mínimos de Serviços e Programas de Atenção à Pessoa Idosa no Brasil. Diário Oficial da União, Brasília, 14 maio 2001.

Senado Federal. Consultoria legislativa. Legislação sobre o idoso [por assunto]. Disponível em: <http://www.senado.gov.br/ web/conleg/idoso/assunto/idoso.htm>.

CONFERÊNCIA NACIONAL DOS DIREITOS DA PESSOA IDOSA. 2006. Anais da I... Brasília: Secretaria Especial dos Direitos Humanos, 2006.

DEBERT, G. G. A reinvenção da velhice. São Paulo: EDUSP, 2004

DUARTE, Y. A. O.; LEBRÃO, M. L.; LIMA, F. D. Contribuição dos arranjos familiares para o suprimento de demandas assistenciais dos idosos com comprometimento funcional em São Paulo, Brasil. Revista Panamericana de Salud Pública, Washington, v. 17, n. 5/6, p. 370-378, 2005.

ELIAS, Pérez Anzola et al. La atención de los ancianos: um desafio para los años noventa. Washington, D.C : OPS, 1994.

ENCONTRO NACIONAL DE CONSELHOS DE IDOSOS. 4., 2006, Brasília. Construindo a Rede Nacional de Proteção e Defesa da Pessoa Idosa - RENADI. Brasília: Secretaria Especial dos Direitos Humanos, 2006.

FALEIROS, Vicente de Paula. Cidadania: os idosos e a garantia dos seus direitos. In. NERI, A. L. Idosos no Brasil: vivências, desafios 
e expectativas na terceira idade. São Paulo: Fundação Perseu Abramo, Sesc, 2007.

FALEIROS, Vicente de Paula. Os conselhos do idoso: controle social e democracia participativa. In: FALEIROS, Vicente de Paula; LOUREIRO, Althair Macedo Lahud, Desafios do envelhecimento: vez sentido e voz. Brasília: Universa, 2006.

GODINHO, Robson Renaut. A proteção processual dos direitos dos idosos. Rio de Janeiro: Lumem Júris, 2007.

ILIFFE, S. et al. A assistência ao idoso em três países. In: GALLO, J. et al. Reichel - Assistência ao idoso: aspectos clínicos do envelhecimento. Rio de Janeiro: Guanabara Koogan, 2001. p. 456-464.

IPEA. Políticas sociais - Acompanhamento e análise. Anexo estatístico, Brasília, n. 10, p. 21-23. fev. 2005.

MESTRINER, Maria Luiza. O estado entre a filantropia e a assistência social.São Paulo:Cortez, 2001

ORGANIZAÇÃO PAN-AMERICANADE SAÚDE (OPAS). Envelhecimento ativo: uma política de saúde. Brasília: Organização Pan-Americana de Saúde, 2005.

RODRIGUES, Nara. PNI: retrospectiva da política nacional do idoso. Revés do Avesso, São Paulo, oํ 14, p. 84-90, out. 2005.

SERVIÇO SOCIAL DO COMÉRCIO (SESC/SP). O Século da terceira idade. São Paulo: SESC/SP, 2003.

SOUSA, Ana Maria Viola. Tutela jurídica do idoso. São Paulo: Alínea, 2004.

WEISSHEIMER, Marco Aurélio. Bolsa Família. São Paulo: Perseu Abramo, 2006. 